\title{
Forensic medicine and the polymerase chain reaction technique
}

\author{
Ronny Decorte, Jean-Jacques Cassiman
}

DNA technology in forensic medicine Forensic scientists have for decades been using serological and electrophoretic methods to determine the origin of blood stains or body fluid samples. ${ }^{1}$ The discrimination potential of these systems is low compared to.certain DNA polymorphisms. Moreover, they rely on the expression of polymorphic proteins and the possibility of detecting a change in a physical property of a protein. ${ }^{2}$ Genetic marker typing at the DNA level is, however, not restricted to genetic variation in coding sequences. In fact, the most polymorphic sites in the human genome lie outside amino acid coding regions. Because of the higher information potential at the DNA level and the presence of DNA in every nucleated cell, forensic scientists introduced recombinant DNA technology in case work samples in the mid 1980s. At that time, Alec Jeffreys showed that highly polymorphic DNA segments (minisatellites or variable number of tandem repeats) are able to generate individual specific DNA 'fingerprints' after hybridisation under low stringency conditions. ${ }^{34}$ It was further shown that reproducible genetic profiles could be produced from dried blood stains (up to four years old), semen stains, hair roots, and blood stains exposed to different environmental conditions..$^{5-9}$

Perhaps the greatest contribution of DNA technology to forensic medicine has been in the identification of rapists. Indeed, the majority of the forensic evidence samples which are submitted for DNA analysis to our forensic laboratory have been derived from sexual assault cases (table 1). In these cases, the vaginal swabs or lavages taken from the victim are often a mixture of spermatozoa and cellular debris (table 2). This poses a problem when serological methods are used for the identification of different polymorphic proteins, es-

Table 1 Distribution according to the offence of 178 case work samples submitted for examination.

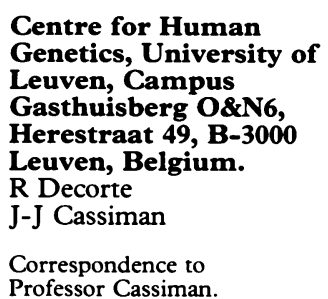

\begin{tabular}{lc}
\hline & $\%$ \\
\hline Violent offences & \\
Rape & $41 \cdot 7$ \\
Murder & $28 \cdot 6$ \\
Homicide & $9 \cdot 0$ \\
Robbery & $7 \cdot 3$ \\
Assault & $1 \cdot 7$ \\
Kidnapping & $1 \cdot 1$ \\
Other offences & $1 \cdot 1$ \\
Car accidents & $1 \cdot 1$ \\
Burglary & $1 \cdot 1$ \\
Blackmail & $7 \cdot 3$ \\
Others &
\end{tabular}

pecially when the number of spermatozoa are quite low. However, it is possible to separate DNA of the sperm nuclei from DNA of the epithelial cells. ${ }^{67}$ The protein coat of the sperm head contains disulphide bridges that can be broken by dithiotreitol (DTT). By differential lysis with a detergent and a proteinase, DNA of the contaminating cells is released while the sperm heads will remain intact (figs 1 and $2 B$ ). The semen cells are recovered by centrifugation and subsequently lysed in the presence of DTT.

Initial procedures for detecting highly polymorphic loci relied on Southern blots and radioactively labelled DNA probes. These methods are sufficiently sensitive (up to $60 \mathrm{ng}$ ) to allow the detection of the different alleles in DNA samples of high molecular weight ${ }^{10}$ : this is usually the case for DNA extracted from blood samples in paternity cases. However, forensic samples in criminal cases do not always contain sufficient non-degraded DNA for analysis of variable number of tandem repeats (VNTR) loci. A report on the stability of DNA in actual case work showed that in $48 \%$ of the samples either degraded or undetectable DNA was present. ${ }^{11}$ Another potential problem is the low resolution of the agarose gels used for sizing restriction fragments. The size differences between two alleles can be between 9 and 70 base pairs and large DNA fragments with such a difference will migrate close to each other and could be typed as one allele instead of two. ${ }^{1213}$

\section{Forensic DNA typing and PCR}

The problems associated with DNA typing of forensic biological samples (for example, insufficient DNA, degraded DNA, resolution of the gels) can be resolved in part by the polymerase chain reaction technique. PCR based typing is simple and has a high sensitivity. ${ }^{14}$ Moreover, it decreases the analysis time to less than one day compared to conventional Southern blot analyses which require at least one

Table 2 Biological evidence samples received for examination.

\begin{tabular}{lr}
\hline & $\%$ \\
\hline Mixed samples: semen + blood or epithelial cells & $41 \cdot 4$ \\
hair & $6 \cdot 8$ \\
Stains of blood or semen (on clothing, glass, knives, etc) & $40 \cdot 9$ \\
Hair & $3 \cdot 2$ \\
Saliva (cigarette butts, envelopes, stamps, etc) & $2 \cdot 8$ \\
Others (bones, teeth, body pieces, etc) & $4 \cdot 9$ \\
\hline
\end{tabular}




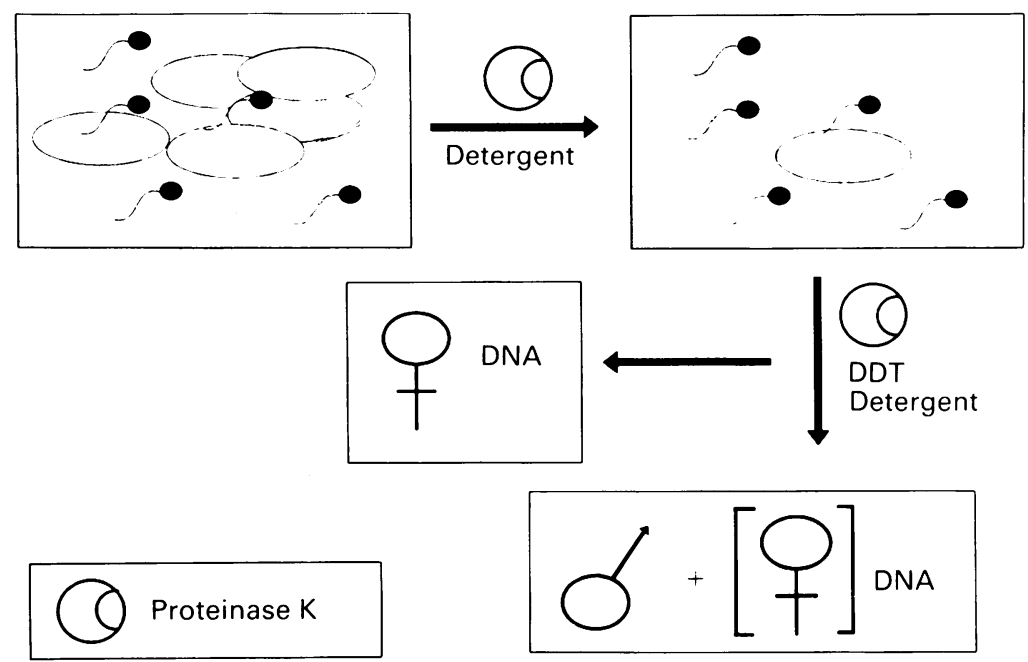

Figure 1 Differential lysis procedure for separation of a mixture of spermatozoa from the assailant and epithelial cells from the victim. week. Degraded DNA is suitable as a substrate for amplification as long as there is at least one DNA fragment present encompassing the two primer binding sites. ${ }^{15}$ The primer sites can be designed to flank directly the repeat regions in VNTR loci so that small differences of one repeat unit can be detected after size fractionation on high resolution gels. This minimises the problem of incomplete resolution of alleles and as a consequence leads to more correct allele frequency estimates. ${ }^{1316}$ In addition, it is possible to construct for each VNTR locus a reference size marker composed of the different amplified alleles observed in a population. This marker is then simultaneously size fractionated with the PCR products to be analysed (fig 2B). It allows for rapid and more correct interpretation of the amplified fragments. ${ }^{17}$ Moreover, a nomenclature based on the number of repeats can be used to label the different VNTR alleles. This would improve
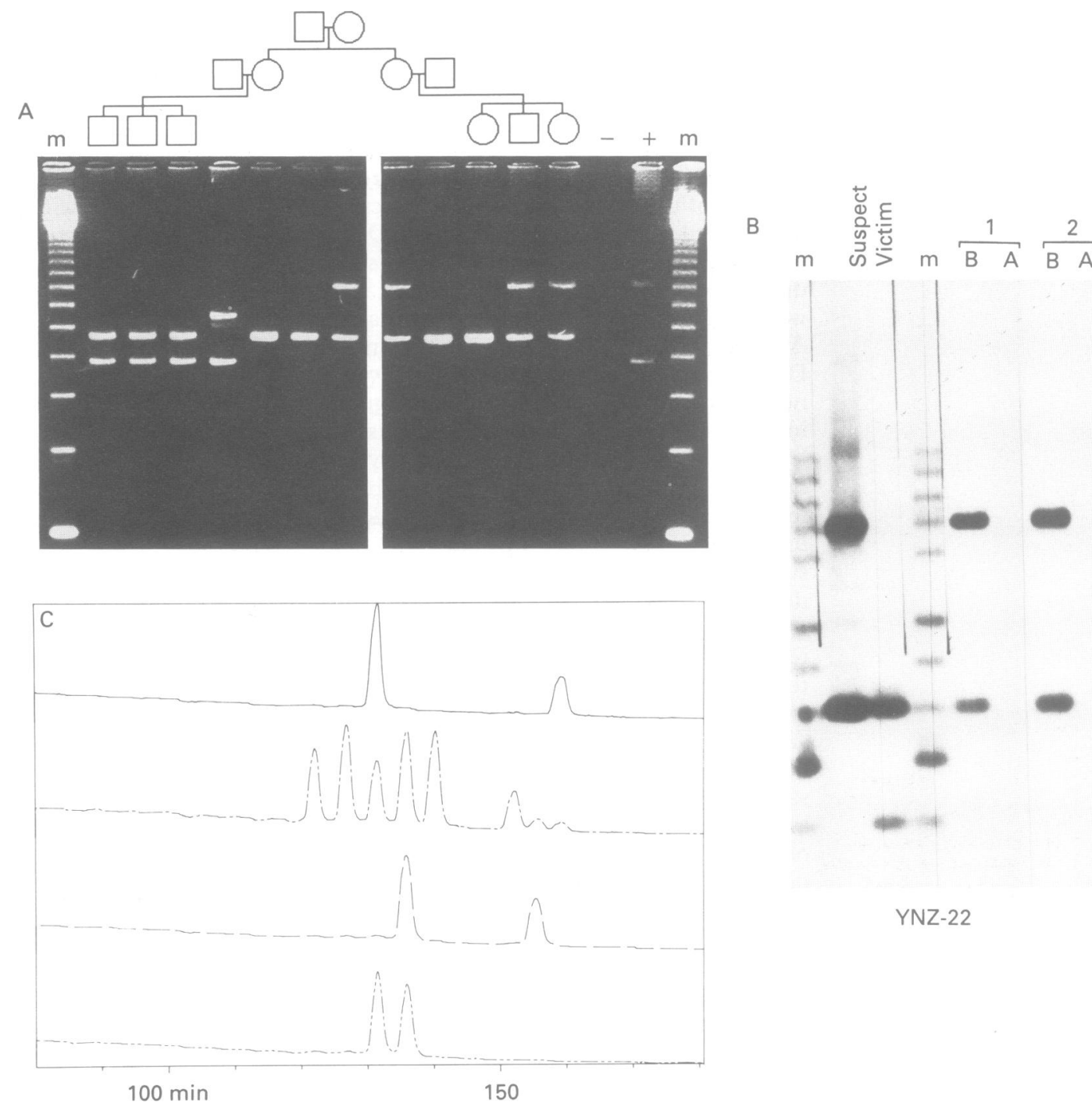

YNZ-22

Figure 2 Detection of amplified VNTR loci by different methods. (A) Segregation of the IGHJ VNTR alleles in a three generation family, size fractionated in a $2 \%$ agarose gel, and visualised with ethidium-bromide $(+=$ positive control, - = negative control, $m=123$ bp ladder (BRL)). (B) Analysis with the VNTR D17S5 of two blood samples (victim and suspect) and two semen stains (1 and 2) on the clothing of the victim, extracted by differential lysis ( $A=$ contaminating $D N A$ from the victim, $B=D N A$ from semen, $m=$ reference marker of amplified alleles). lysis $(A=$ contaminating $D N A$ from the victim, $B=D N A$ from semen, $m=$ reference marker of amplified alleles).
Amplified fragments were labelled during $P C R$ with biotin-1 1 -dUTP and detected after Southern transfer with avidin alkaline phosphatase and chemiluminescence. The result showed no contaminating cells from the victim. (C) Population screening with the APOB VNTR: alleles were amplified with one of the primers labelled with fluorescein; PCR fragments were size fractionated in a 4\% Hydrolink Long Ranger gel on a Pharmacia ALF automated DNA sequencer. 
standardisation and allow for exchange of data between forensic laboratories.

Because of the high sensitivity of PCR, one does not need large amounts of DNA for typing polymorphisms. This has the advantage that repeated analysis is possible in case of technical failure or when confirmation of the results is necessary. Defence lawyers are becoming aware of the high inclusion probabilities with DNA typing methods and are often requesting a second opinion. ${ }^{18} 19$ Therefore, if only minute DNA samples are used for the analysis, enough DNA will be left for a second analysis in another forensic laboratory. In contrast, conventional DNA typing needs at least 50 to $500 \mathrm{ng}$ of high molecular weight DNA, and in most cases repeat analysis is not possible.

The use of PCR for the analysis of DNA from evidence samples has also made it possible to use other material which could connect certain subjects with a crime (table 2 ). Reference DNA samples from suspects and victims do not always have to be blood samples; buccal epithelial cells, single hairs, epithelial cells from urine, and even fingernails can be used as a source of DNA. ${ }^{20-23}$ Cigarette butts contain saliva, but only small amounts of DNA (10 to $100 \mathrm{ng}$ ) can be extracted which is insufficient for Southern blot analyses. ${ }^{24}$ Saliva on stamps and on the seals of envelopes, although in small amount ( $R$ Decorte, unpublished results), can be a source of biological material useful in the identification of persons involved in blackmail or ransom letters. Bones and teeth are sometimes available as evidence of murders committed several years in the past or from homicides in which the victim was not found promptly. ${ }^{25-27}$ After death, human organic tissue rapidly decomposes and at the same time DNA in dead cells degrades under the influence of endonucleases and exonucleases. After a few years, only skeletal remains can be found. Therefore, skeletons are important biological samples not only in forensic science but also in anthropology and archaeology. 2829

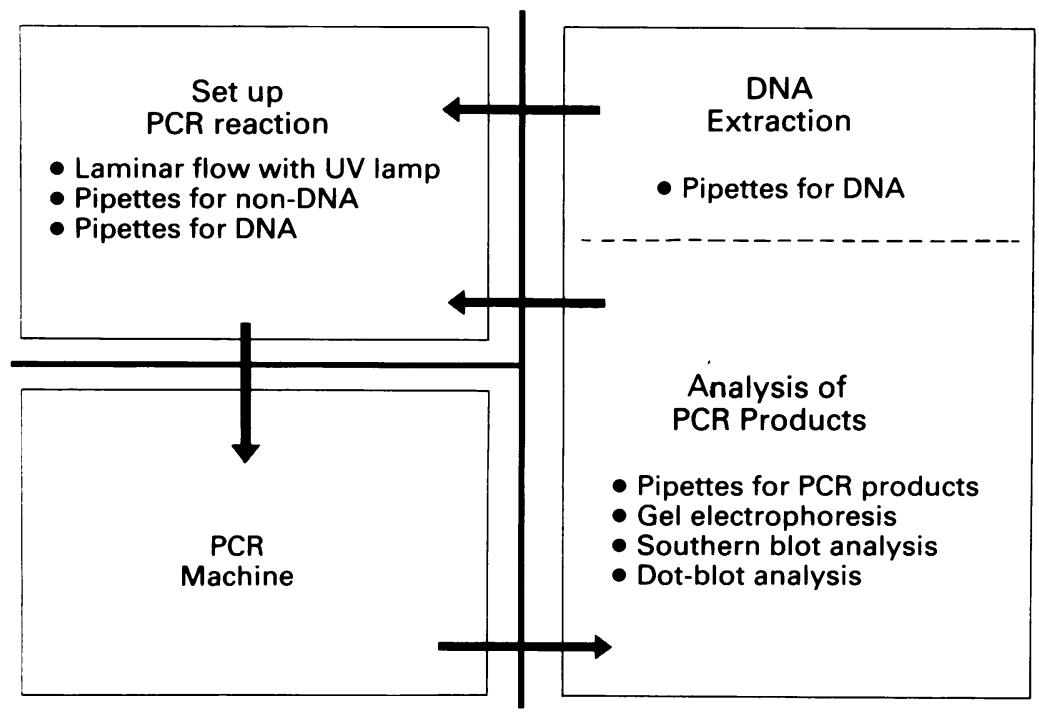

Figure 3 Laboratory situation and precautions for avoiding contamination in PCR based typing of genetic polymorphisms.

\section{Special concerns in PCR}

The remarkable sensitivity of the polymerase chain reaction raises special concerns about the accidental contamination of the DNA samples or PCR reactions. The most important form of contamination is carry over of amplified DNA from previous amplifications. As a consequence false positive results can be obtained which could lead to incorrect conclusions and in an extreme case might exclude or include suspects from being involved in a crime. It is therefore of extreme importance to take the necessary precautions in order to avoid contamination (fig 3). This is not only true for forensic laboratories but also for clinical settings where PCR is used as a routine diagnostic tool. Carry over of PCR products can be prevented by physical separation of the areas for DNA extraction, setting up of the amplification reactions, and analysis of the PCR products. One should exclude tubes with PCR products from the environment where DNA extractions are performed. Furthermore, separate pipetting devices and the use of positive displacement pipettes should help to limit the possibility of accidental contamination of the DNA samples or the PCR reactions. Additional recommendations have also been formulated by Kwok and Higuchi. ${ }^{30}$

Another potential source of contamination is DNA from cells which have been introduced into the samples either before the biological evidence arrived in the laboratory or during the extraction procedure. Some experts have minimised this problem of contamination during manipulation by stating that the sensitivity level (amount of DNA) at which they perform PCR is not enough to detect these contaminations. ${ }^{31}$ However, one should be aware of the possibility of contamination and take the appropriate measures. In the laboratory, contamination can be avoided in addition to the physical separation of the DNA extraction by scheduling the extraction of biological samples with low amounts of DNA at a different time from the reference samples (blood samples) from suspect or victim. Furthermore, the laboratory personnel should be typed and all the results should be checked against their genotypes.

Outside the forensic laboratory, it is difficult to exclude contamination of the samples. Therefore, law enforcement agencies have to be told about the risk of contamination of the evidence with saliva or hair and they have to take the necessary precautions in order to avoid accidental contamination. In a forensic laboratory, one can control for external contamination of the evidence sample by extracting some unstained pieces of material of the same evidence. This unstained material would not contain any biological fluid and therefore should be a good negative control. If it gives a positive result one can compare the result first with the genetic typings of the laboratory personnel in order to exclude internal contamination, and then with the typings of the stained material. If no match can be found, contamination by other persons, such as policemen, cannot be excluded. 
PCR based DNA typing systems

VNTRS AND MICROSATELLITES

In the past few years, a PCR based method has been developed for a large number of different polymorphic loci some of which have been applied in forensic investigations (table 3). The majority of these loci are insertion/deletion polymorphisms such as VNTRs or microsatellites. It is not surprising that these loci are the most popular ones because VNTRs were already used in conventional DNA typing. Typing of insertion/deletion polymorphisms by PCR involves only amplification and size fractionation on gel and staining with ethidium bromide or silver in order to detect the different alleles ${ }^{36374647}$ (fig 2A). However, for degraded DNA or small samples of DNA it is not always possible to detect the amplified fragments directly after size fractionation. Furthermore, DNA samples from biological stains from scenes of crime are often contaminated with non-human DNA (bacterial or fungal) which makes it necessary to quantify the proportion of human DNA. ${ }^{48}$ One could raise the number of cycles in order to detect directly the different amplified alleles with ethidium bromide. This alternative is, however, not always applicable for VNTR regions because an excessive number of amplification cycles will result in the generation of additional aberrant fragments, which will interfere with the actual typing. These background fragments are thought to be the result of incomplete PCR products which act as primers in the additional cycles. $^{3237}$ Because of the repeat structure of the VNTR region, they can prime at several sites and give rise to smaller or larger fragments differing in a number of repeats from the original alleles present in the DNA sample. The number of cycles must therefore be limited in order to avoid such problems.

A Southern transfer followed by a hybridisation with a labelled DNA probe can be performed in order to detect the amplified VNTR alleles. ${ }^{32}$ An alternative is the incorporation during the amplification reaction of a hapten such as biotin ${ }^{33}$ or digoxigenin. ${ }^{49}$ This allows for direct detection after Southern transfer through an intermediate enzyme complex (for example, avidin-alkaline phosphatase) and chemiluminescence (fig 2B). This method is sensitive and rapid and avoids the use of radioactivity. Ultimately, one can incorporate a

Table 3 PCR detection of DNA polymorphisms which have been used in forensic medicine.

\begin{tabular}{lllcl}
\hline Name & $\begin{array}{l}\text { HGM11 } \\
\text { locus }\end{array}$ & $\begin{array}{l}\text { Chromosome } \\
\text { localisation }\end{array}$ & $\begin{array}{l}\text { Heterozygosity } \\
(\%)\end{array}$ & Reference \\
\hline p33.4 & D1S118 & 1 & 67 & $3233 \dagger$ \\
p33.6 & D1S111 & lq23 & 78 & $32 \dagger$ \\
pMCT118 & D1S80 & 1p36-p35 & 81 & 3435 \\
Apolipoprotein B & APOB & 2p23-p24 & 77 & 363738 \\
Gc & GC & $4 \mathrm{q} 12-\mathrm{q} 13$ & $*$ & 39 \\
DQA1 & HLA-DQA1 & $6 \mathrm{p} 21.3$ & 82 & 404142 \\
DRB1 & HLA-DRB1 & $6 \mathrm{p} 21.3$ & 90 & 41 \\
C4A and B & C4A; C4B & $6 \mathrm{p} 21.3$ & $*$ & 43 \\
ABO & ABO & $9 \mathrm{q} 34.1-\mathrm{q} 34.2$ & 6 & 44 \\
c-Ha-ras & HRAS & $11 \mathrm{p} 15.5$ & 68 & 37 \\
Type II collagen & COL2A1 & $12 \mathrm{q} 14.3$ & 81 & 45 \\
p3.4BHI & IGHJ & $14 \mathrm{q} 32.33$ & 74 & 37 \\
pYNZ22 & D17S5 & $17 \mathrm{p} 13$ & 85 & $46 \dagger$ \\
p602 & DXYS17 & Xp22.3/Yp11.3 & 84 & $\dagger$ \\
\hline
\end{tabular}

*Heterozygosity unknown for PCR detectable alleles.

$\dagger R$ Decorte et al, in preparation. fluorescent dye into the PCR products during amplification followed by the detection of the amplified products with a laser detection system on an automated sequencer ${ }^{50-52}$ (fig 2C). This system is very sensitive and allows for complete automation of the analysis of the DNA samples. Moreover, software is available for the determination of the fragment sizes of the amplified fragments and output can be routed to database packages for evaluation or storage. Finally, it is also possible to reamplify the PCR products with a nested ${ }^{38}$ or heminested primer pair ${ }^{53}$ ( $\mathrm{R}$ Decorte et al, in preparation). This way a sufficient quantity of amplified fragments is obtained for detection on gel with ethidium bromide. It has also the advantage of increasing the sensitivity of the assay to a single cell or sperm. ${ }^{53}$

Another problem in PCR typing of VNTR loci is the efficiency of the amplification of VNTR regions. Shorter alleles are preferentially amplified compared to longer alleles which will result in a molar imbalance between short and long allele products. ${ }^{32} 37$ Alleles differing in size by a few hundred base pairs will be amplified without any problem but when the difference is several $\mathrm{kb}$, the longest alleles tend not to be detected. Therefore, it is not surprising that most PCR based typing methods for VNTR regions have been reported for a limited number of loci with an allele size of less than 3000 base pairs.

Amplification of microsatellite regions does not cause many problems mainly because of the smaller size of the region to be amplified and the size distribution of the different alleles. Additional amplification products are observed only for dinucleotide and some trinucleotide repeats. These fragments are probably the result of DNA slippage of the Taq DNA polymerase enzyme. Tetra- or pentanucleotide repeats do not show these additional amplification products and are therefore more suitable for forensic investigations and for presentation in a court room..$^{54}$

Microsatellites are abundant in the human genome: dinucleotide repeats occur approximately every $6 \mathrm{~kb}^{55}$ and tri- or tetranucleotide repeats every 300 to $500 \mathrm{~kb}^{54}$ The polymorphism information content of these markers is lower than for VNTR regions but because of the abundance and the simplicity of amplification and typing, the same informativeness can be obtained with a slightly higher number of loci. Moreover, multiplex PCR or pooling of different amplification reactions allows for high throughput of information as long as the allele size distributions do not overlap. In addition, the use of a laser detection system allows for automation of the analyses. ${ }^{54}$ This system also alleviates the problem of radioactivity which is currently used for detection of microsatellites on a sequencing gel.

Because of the small PCR products (100 to $500 \mathrm{bp}$ ), microsatellites are extremely useful for typing degraded DNA samples. While routine forensic DNA samples show some degradation, VNTR regions can be typed by PCR although they are less efficiently amplified. For highly degraded DNA samples, such as DNA 
extracted from bone fragments and teeth, VNTRs cannot be typed because the bulk of the degraded DNA is below the allele sizes of the VNTR (R Decorte, unpublished results). ${ }^{25}$ Microsatellites and other polymorphic systems with small PCR products can then be used, usually without any problem.

HLA

Other highly polymorphic sequences commonly used for forensic investigations are the human leucocyte antigen (HLA) class II genes (table 3). In the past few years, knowledge about the sequence differences which are the basis for the great diversity among these major histocompatibility genes has grown rapidly. This was only possible after the development of the polymerase chain reaction technique and rapid techniques for sequencing PCR products without going through a cloning step. ${ }^{56}$ The molecular basis for the diversity of the major HLA class II genes is clustered into three hypervariable regions in the second exons of the DQA1, DQB1, DRB1, and DPB1 genes. Detection of these differences can be accomplished by amplification of this exon followed by hybridisation with sequence specific oligonucleotides. ${ }^{57}$ Because of the great variability, it is not always possible to identify each allele with only one oligonucleotide. Sequence specific oligonucleotides will detect more than one allele and it is the combination of several oligonucleotides which will finally identify the alleles and the genotype. Standard dot blot

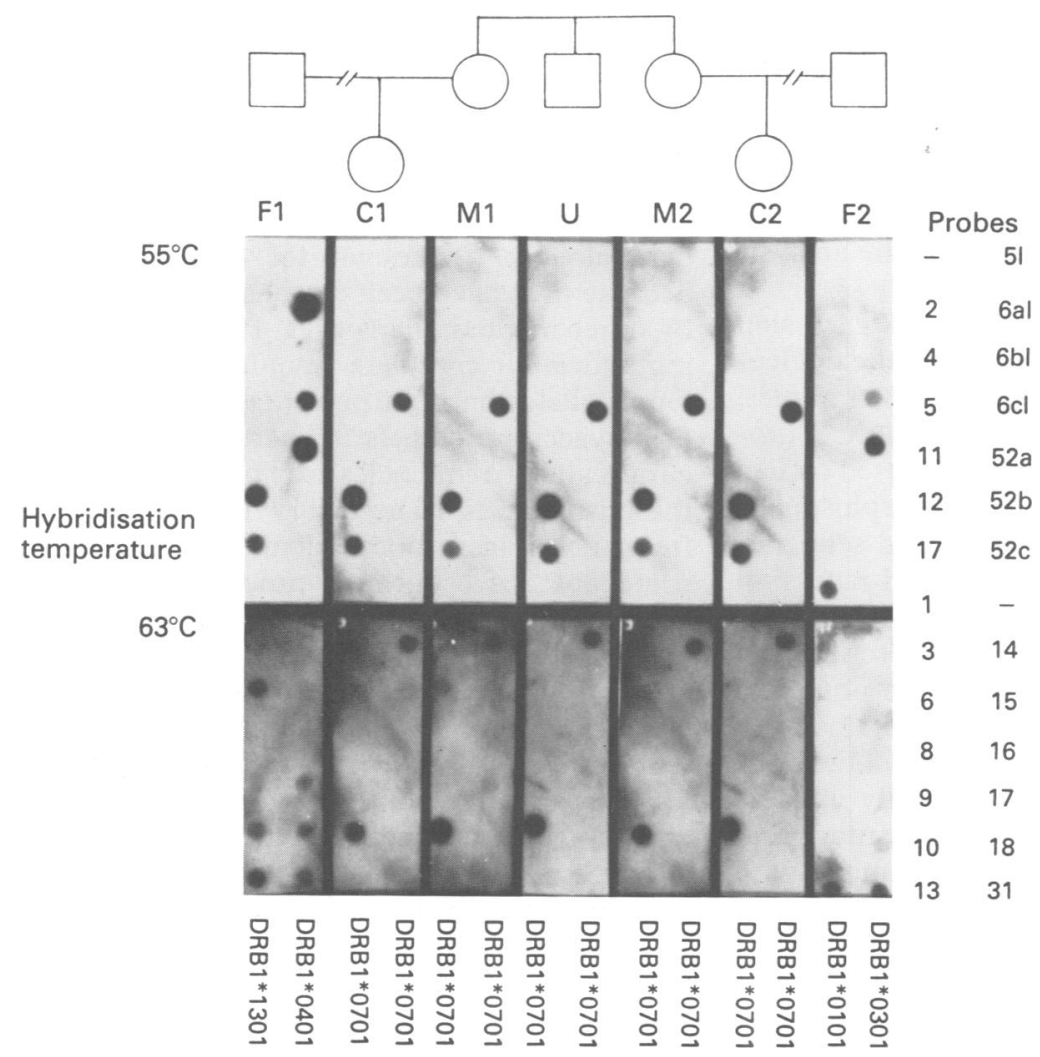

Figure 4 Paternity analysis with the HLA-DRB1 system in a family with evidence of incest. DNA from blood samples was amplified for the second exon of the DRB1 gene in the presence of biotin-11-dUTP. Amplified fragments were genotyped with a reverse dot blot assay. The legal fathers of the two girls could be excluded as the biological fathers. The uncle of the two girls was shown to be their father. This result was confirmed with seven different VNTRs. typing in which the PCR products are fixed on membranes and the membranes are hybridised with labelled oligonucleotides is a long and laborious procedure. An alternative approach is the immobilisation of oligonucleotides on the membranes and hybridisation with the PCR products which were labelled during amplification. ${ }^{4041}$ This method, which has been termed the reverse dot blot technique, has the advantage that only one hybridisation has to be performed, one for each DNA sample. Furthermore, a non-radioactive detection system based on biotin and alkaline phosphatase followed by a colorimetric or chemiluminescent system is used for the identification of the positive hybridisation spots.

At the end of the 1970s, HLA typing was introduced in the forensic laboratory for paternity testing. This involved mainly the serological typing of class I genes $(A, B$, and $C$ ) while HLA-DRB1 has also been used extensively. The DRB1 gene is the most polymorphic among the HLA class II genes with 60 known different alleles. ${ }^{58}$ An amplification and reverse dot blot assay has been developed in our laboratory and is able to discriminate 52 of the 60 possible alleles. With this system, the probability for paternity exclusion is 0.80 while the power for discrimination is 0.98 . It is therefore one of the most informative marker systems based on PCR detection and analysis. However, for mixed samples, such as the vaginal swabs obtained after rape, it is not always possible to identify each genotype because of the complexity of determining the alleles. As a consequence, the HLA-DRB1 system is not always as applicable to forensic samples as it is for paternity determinations (fig 4). The DQA1 system is less complex and therefore more interesting for forensic use. The DQA1 system was also the first commercial forensic PCR-DNA typing system on the market and is at present probably the most validated PCR system in forensic laboratories. ${ }^{425960}$ However, only nine of the 13 DQA1 alleles are identified by this kit with three alleles assigned as a single allele. Two of these three alleles have a frequency of 0 to $5 \%$ in white populations while in North American blacks the two alleles are found with a frequency of $15 \%$ (11th International Histocompatibility Workshop and Conference, Central Data Analysis Committee, Yokohama, 1991). Moreover, a study of the HLA-DQA 1 diversity in a Hispanic and a south-east Asian population has shown a slight excess of homozygotes which could be an indication for the presence of a null allele (an allele undetectable with the PCR system) or an undiscriminated allele (two different alleles identified as only one). ${ }^{42}$ The power of the commercial PCR kit is probably maximal in a white population but could be reduced in other populations. The DQA1 system, which we have developed, is also able to identify nine out of 13 alleles but can distinguish those alleles undiscriminated by the commercial HLADQA1 kit. As a consequence, more accurate typing results can be obtained. ${ }^{41}$ 
OTHER PCR BASED TYPING SYSTEMS

Progress in the identification of genes and their gene products has also led to the isolation of the genes encoding for a number of serological proteins and blood groups such as the complement component $\mathrm{C} 4$, the group specific component (Gc), and the $\mathrm{ABO}$ blood groups. Elucidation of the genetic differences responsible for the polymorphisms have made it possible to develop amplification procedures for typing different gene products. ${ }^{39} 4344$ Moreover, genetic typing of genes for which serological methods have been in use in the forensic laboratory for decades circumvents the problem of dependability on the expression of the gene. Typing of these polymorphisms can be done directly by allele specific amplification, by restriction enzyme analyses after PCR, or by hybridisation with allele specific oligonucleotides. Allele specific amplification is a technique which has been developed in recent years. The goal of this method is the rapid identification of single base polymorphisms without the need for additional analysis (restriction digestion or hybridisation) after amplification. Specific alleles are detected by amplification using a primer with a $3^{\prime}$ end which is complementary to one of the two alleles: if the allele is present in the DNA sample an amplification product is obtained, while in the absence of the allele no amplification is seen. However, this PCR method is sometimes difficult to control and it may be more subject to variation especially in forensic case samples. Therefore, the transfer from development to actual case work should only be done after an extensive evaluation period with forensic evidence samples. Moreover, the National Research Council Committee on DNA Technology in Forensic Science in the United States (NRC Committee) has recommended that the allele specific amplification technique should not be used for the analysis of forensic evidence samples. ${ }^{61}$

Ultimate proof for inclusion or exclusion may only be feasible by comparing the nucleotide sequences of the two DNA samples. Direct enzymatic sequencing of the PCR products is possible and should be focused on loci which have a high degree of polymorphism in a region small enough to amplify and sequence in one step. Because of the diploid nature of nuclear DNA, a complex pattern of heterozygosity at multiple sites in the PCR product and in the sequencing result would be obtained. Mitochondrial DNA, however, contains a region (control region or D loop) of 1122 base pairs that is composed of two highly variable segments. The mtDNA has the advantage that it is a haploid circular DNA segment with multiple copies present in each cell. Sequence variation in the variable segments can be determined by PCR and direct sequencing of the PCR products. Rapid and automated sequencing is obtained with a solid phase biotin approach in combination with a fluorescent labelled sequence primer. ${ }^{62}$ The diversity value in different populations exceeds 0.95 which makes it extremely useful for the determination of maternal lineage and for forensic purposes. ${ }^{63}$ In fact, hair samples are very often found at the scene of the crime or on the body of the victim or the suspect (table 2). Most of these hairs are shed hairs and do not contain a hair root. Without a hair root, it is difficult to type nuclear DNA polymorphisms because the cell nucleus is eliminated during the process of keratinisation. In contrast, the hair shafts still contain multiple copies of mtDNA. ${ }^{20}$ Moreover, hair samples could have different origins (persons) which makes it necessary to type individual hairs.

\section{Procedure for PCR based typing}

The analysis of different loci by PCR should fit a number of different criteria: (1) the locus has to be very polymorphic, (2) typing by PCR should be uncomplicated with detection of all possible alleles, and (3) population genetic data (allele distribution and mutation frequency) should be known. The different loci described in table 3 are less polymorphic than some of the VNTR loci which have been used in conventional DNA typing. As a consequence, more loci have to be typed in order to obtain the same exclusion or inclusion probability. On the other hand, there is a direct relation between the mutation frequency and the heterozygosity for VNTR loci. ${ }^{64}$ Although mutations have not been described for the different VNTR loci which can be detected by PCR except for D17S5, one should be aware of it in paternity studies. It is therefore advisable to take a safe approach by not limiting exclusion to only one locus. In forensic evidence samples, a germline mutation will not interfere with the results because the samples have been derived from a single person. Somatic mutations do occur and could give an exclusion if one only typed a single cell.

The distribution of alleles in the population may already be known for particular loci because they have been established previously by other methods. However, PCR based typing allows for complete resolution of the different alleles on high percentage agarose gels or polyacrylamide gels. ${ }^{65}$ Therefore, more accurate allele frequencies can be obtained but this also makes it necessary to redefine the frequencies in a population with the PCR protocols. ${ }^{16}$ An optimal procedure for the analysis of forensic evidence or paternity DNA samples should be based on the polymorphic information content of the system and on the cycling parameters for amplification. ${ }^{65}$ This will ensure that most information is obtained in a reasonably short time. One could even amplify two or three different loci simultaneously but this is only feasible when the allele size distributions of the loci do not show any overlap. In addition, multiplex amplification should only be used on DNA samples of good quality.

Initial analysis with two or three different polymorphic loci should give an idea about inclusion or exclusion in paternity cases or a match in forensic cases. An approach with only three VNTR loci (DXYS17, D1S111, and D17S5), which have the same cycling para- 
meters, has shown in actual paternity case work that at least one exclusion was observed in $94.7 \%$ of the non-paternity samples ( $R$ Decorte, unpublished results). A second exclusion or even a third was observed in $76.6 \%$ of the non-paternity samples. This means that when the disputed father is not the biological father of the child, we are able to exclude him in about $75 \%$ of the cases with only three VNTR loci which can be done in two days.

\section{DNA typing in court}

The application of DNA technology to forensic samples has rapidly become accepted by courts all over the world. Its potential to exclude wrongly accused suspects in murder or rape cases is not in dispute and is a success compared to the low exclusion probability of conventional serology. However, the high inclusion probability of DNA typing has raised some concern by some biologists and legal experts. ${ }^{66}$ Criticism about the use of DNA technology for the identification of suspects has initially focused on the methodology but it has steadily moved to the level of population genetics and the statistical evaluation of the results. ${ }^{12}$ Over the past few years, RFLP methods have been optimised and improved. International cooperation either by forensic laboratories (for example, EDNAP = European DNA Profiling group) or by commercial laboratories (for example, Cellmark) has led to quality assurance programmes. These programmes are based on standardisation of laboratory protocols and frequent (every three to six months) typing of unknown mock case samples. The ultimate goal is to standardise DNA profiling (protocols and VNTR probes) which would allow for exchange of data or forensic samples between laboratories. The benefit of PCR in this context is that it is easy to transfer the protocols to other laboratories and that the way of identifying the different amplified VNTR alleles can be standardised by using size markers composed of amplified VNTR alleles. ${ }^{17}$

When two band patterns do not match (for example, suspect and stain), the conclusion will be that the suspect/victim could not be the donor of the stain. In case of a match, the court wants to know the significance of this event, or what the probability is that somebody else has committed the crime. In answering this question, the forensic expert calculates the population frequencies of the genotypes for the different loci. For this reason, the frequency of occurrence of the alleles has to be known. They are usually obtained by typing a random sample of the population which is sufficiently large to provide a good estimate of the actual allele frequency. However, the inability to discriminate two large alleles differing in size by one repeat unit is a technical problem in conventional DNA typing and is hard to overcome. As a consequence, it is not possible to obtain a discrete allele frequency distribution for most VNTR regions if Southern blot analysis is performed. Instead, a quasi-continuous distribution is obtained and in order to have allele frequency estimates, it is necessary to set some arbitrary boundaries for the band size which has been called 'binning' ${ }^{67}$ With PCR, however, a discrete allele distribution can be obtained which gives more correct allele frequency estimates. ${ }^{16}$ The frequency estimates are then used to calculate the probability of a match with the assumption that the data set is in Hardy-Weinberg equilibrium. Deviations from this rule are sometimes reflected in the observation of an excess of homozygotes compared to the expected number. There could be several explanations for this phenomenon: (1) the presence of null alleles, (2) incomplete resolution of two closely spaced but different alleles which has been called pseudo-homozygosity, or (3) population substructure. In forensics, it is appropriate to use reference data on the population from which the suspect originated. One genotype could be very frequent in a white population but rare in a black population. This will influence the significance of a match by a factor 10 to 100 . If the reference data have been obtained from a mixed population then the difference between the exact population and the mixed population frequencies would be even less pronounced. ${ }^{1368}$ Nevertheless, it is advisable to take a conservative approach and calculate the probability of a match by using $p$ (= allele frequency estimate) or even a $2 p$ statistic for a single band pattern instead of $\mathrm{p}^{2}$. One should also not take into account the alleles shared with the other persons (suspects or victim) who are involved in the case. All these methods will ensure that the frequency estimates are biased in favour of the suspect.

Finally, to overcome population substructure or ethnic background of a subject, the NRC Committee has recommended the use of the 'ceiling principle': the highest frequency found in 15 to 20 different populations (each 100 persons typed) would be used or $5 \%{ }^{69}$ Recently, the NRC proposal has come under attack by population geneticists and statisticians arguing that there is no scientific basis for the 'ceiling principle' and that it is built on erroneous assumptions about population genetics (subpopulations within ethnic groups show a higher diversity than the major group).$^{70}$ It also does not take into account the fact that the suspect may not belong to the ethnic group of which the allele frequency estimate has been used to calculate the significance of the match. An alternative approach would be to use a likelihood ratio (LR) which is simply the inverse of the genotype probability. ${ }^{71}$ The LR is also comparable with the paternity index (PI) which is frequently used for evaluating disputed paternity cases.

\section{Future perspectives} TECHNOLOGY

Automation of the PCR process has been one of the first innovations after the introduction of PCR technology. Additional automation is at this moment under development firstly in size separation of the amplified fragments, 
secondly in the preparation of PCR reactions, and thirdly in sequencing. Robotic work stations can prepare the PCR reactions in a 96 well microplate format including the addition of the DNA samples. Sequencing of the PCR products can be taken over by automatic sequencing robots and finally automatic loading devices can load the sequencing reactions or the amplified PCR products onto automatic sequencers. The role of the laboratory personnel is limited and involves only programming of the robot, supplying the correct solutions, and evaluation of the results.

\section{ADDITIONAL MARKERS}

Some of the most promising markers are the minisatellite variant repeats (MVR). Jeffreys $e t$ $a l^{2}$ have observed that not only the number of repeats of minisatellite or VNTR regions can be different but also that the repeats themselves can be polymorphic at the nucleotide level. These polymorphisms are sometimes detectable by restriction enzymes but also by allele specific amplification. It is possible that two alleles of the same length can have a different composition in repeat nucleotide sequence. This has important consequences for forensic analysis when one uses only a single VNTR locus or when one only has a result with one polymorphic marker: the matching band pattern could be an exclusion if one knew the exact base composition of the matching alleles. Analysis of the internal variation either by restriction digestion or by allele specific amplification is independent of artefacts like band shifting which occurs sometimes in conventional DNA typing. Side by side comparison is not necessary with this method as is the case with current technology for the analysis of VNTRs. Moreover, the patterns generated can be stored as a binary ( $1=$ present, $0=$ absent $)$ code which suggested the name 'digital DNA typing' for this method. ${ }^{73}$ It allows for easy comparison in large databases because it does not have to take into account size measurement errors. The efficiency for paternity testing is, however, limited by the high mutation rate at the minisatellite loci which have these internal variations. Furthermore, as explained before, allele specific amplification is more subject to variation in experimental conditions and should therefore only be used after extensive evaluation.

\section{Conclusions}

The polymerase chain reaction technique has become a valid alternative to Southern blotting for the detection of highly polymorphic loci such as variable number of tandem repeats. It has not only facilitated the analysis of genetic polymorphisms but it has also opened the way for the use of new markers such as microsatellites and the mitochondrial control region. Because of the simplicity of the protocols, it allows for standardisation and exchange of data with other forensic laboratories. The higher sensitivity and the increased resolution of small size differences increases the number of cases in which a result can be obtained and allows for more accurate statistical calculation. PCR based typing of forensic case samples should, however, be performed with the strongest precautions against contamination. This will ensure that forensic DNA analysis is reliably performed to the highest standard.

1 Sensabaugh GF. Uses of polymorphic red cell enzymes in forensic science. Clin Haematol 1981;10:185-207.

2 Divall GB. The application of electrophoretic techniques in the field of criminology. Electrophoresis 1985;6:249-58.

3 Jeffreys AJ, Wilson V, Thein SL. Hypervariable 'minisatellite' regions in human DNA. Nature 1985;314:67-73.

4 Jeffreys AJ, Wilson V, Thein SL. Individual-specific 'fingerprints' of human DNA. Nature 1985;316:76-9.

5 Gill P, Jeffreys AJ, Werrett DJ. Forensic applications of DNA 'fingerprints'. Nature 1985;318:577-9.

6 Kanter E, Baird M, Shaler R, Balazs I. Analysis of restriction fragment length polymorphisms in deoxyribonucleic acid (DNA) recovered from dried bloodstains. $\mathcal{F}$ Forensic Sci 1986;31:403-8.

7 Giusti A, Baird M, Pasquale S, Balazs I, Glassberg J. Application of deoxyribonucleic acid (DNA) polymorphisms to the analysis of DNA recovered from sperm. $f$ Forensic Sci 1986;31:409-17.

8 Gill P, Lygo JE, Fowler SJ, Werrett DJ. An evaluation of DNA fingerprinting for forensic purposes. Electrophoresi 1987;8:38-44.

9 McNally L. Shaler RC, Baird M, Balazs I, De Forest P, Kobilinsky L. Evaluation of deoxyribonucleic acid (DNA) isolated from human bloodstains exposed to ultraviolet light, heat, humidity, and soil contamination. $\mathcal{f}$ Forensic Sci 1989;34:1059-69.

10 Wong Z, Wilson V, Patel I, Povey S, Jeffreys AJ. Characterization of a panel of highly variable minisatellites cloned from human DNA. Ann Hum Genet 1987;51:26988 .

11 McNally L, Shaler RC, Baird M, Balazs I, Kobilinsky L, De Forest $P$. The effects of environment and substrata on deoxyribonucleic acid (DNA): the use of casework samples from New York City. $\mathcal{f}$ Forensic $S c$ 1989;34:1070-7.

12 Lewontin RC, Hartl DL. Population genetics in forensic DNA typing. Science 1991;254:1745-50

13 Chakraborty R, Kidd KK. The utility of DNA typing in forensic work. Science 1991;254:1735-9.

14 Mullis K, Faloona F, Scharf S, Saiki R, Horn G, Erlich H. Specific enzymatic amplification of DNA in vitro: the polymerase chain reaction. Cold Spring Harbor Symp Quant Biol 1986;51:263-73.

15 Impraim CC, Saiki RK, Erlich HA, Teplitz RL. Analysis of DNA extracted from formalin-fixed, paraffin-embedded tissues by enzymatic amplification and hybridization with tissues by enzymatic amplification and hybridization with sequence-specific oligonucle

16 Chakraborty R, Fornage M, Gueguen R, Boerwinkle E. Population genetics of hypervariable loci: analysis of PCR based VNTR polymorphism within a population. In Burke $\mathrm{T}$, Dolf $\mathrm{G}$, Jeffreys $\mathrm{AJ}$, Wolff $\mathrm{R}$, eds. $D N A$ fingerprinting. Approaches and applications. Basel: Birkhäuser Verlag, 1991:127-43.

17 Sajantila A, Puomilahti S, Johnsson V, Ehnholm C. Amplification of reproducible allele markers for amplified fragment length polymorphism analysis. Biotechniques 1992;12:16-21.

18 Levy HA. DNA evidence in criminal cases: legal developments. New York Law f 1990;203:1-6.

19 Wooley J, Harmon RP. The forensic DNA brouhaha: science or debate? Am f Hum Genet 1992;51:1164-5.

20 science or debate? Am f Hum Genet 1992;51:1164-5. HA. DNA typing from single hairs. Nature 1988;332:543-6.

21 Lench N, Stanier P, Williamson R. Simple non-invasive method to obtain DNA for gene analysis. Lancet 1988;i:1356-8.

22 Gasparini P, Savoia A, Pignatti PF, Dallapiccola B, Novelli $\mathrm{G}$. Amplification of DNA from epithelial cells in urine. $N$ Engl f Med 1989;320:809.

23 Kaneshige T, Takagi K, Nakamura S, Hirasawa T, Sada $\mathrm{M}$, Uchida $\mathrm{K}$. Genetic analysis using fingernail DNA Nucleic Acids Res 1992;20:5489-90.

24 Hochmeister MN, Budowle B, Jung J, Borer UV, Comey CT, Dirnhofer R. PCR-based typing of DNA extracted from cigarette butts. Int $\mathcal{F}$ Leg Med 1991;104:229-33.

25 Hagelberg E, Gray IC, Jeffreys AJ. Identification of the skeletal remains of a murder victim by DNA analysis. Nature 1991;352:427-9.

26 Dix JD, Stout SD, Mosley J. Bones, blood, pellets, glass, and no body. F Forensic Sci 1991;36:949-52.

27 Ginther C, Issel-Tarver L, King MC. Identifying individuals by sequencing mitochondrial DNA from teeth. vature Genet 1992;2:135-8.

28 Hagelberg E, Clegg JB. Isolation and characterization of DNA from archaeological bone. Proc $R$ Soc Lond $B$ 1991;244:45-50.

29 Cherfas J. Ancient DNA: still busy after death. Science 1991;253:1354-6.

30 Kwok S, Higuchi R. Avoiding false positives with PCR

Nature 1989;339:237-8.
31 Reynolds R, Sensabaugh G, Blake E. Analysis of genetic 
markers in forensic DNA samples using the polymerase chain reaction. Anal Chem 1991;63:2-15.

32 Jeffreys AJ, Wilson V, Neumann R, Keyte J. Amplification of human minisatellites by the polymerase chain reaction: towards DNA fingerprinting of single cells. Nucleic Acids Res 1988;16:10953-71.

33 Decorte R, Hilliker C, Marynen P, Cassiman JJ. Rapid and simple detection of minisatellite regions in forensic DNA samples by the polymerase chain reaction combined with a chemiluminescence method. Trends Genet 1990;6:1723 .

34 Kasai K, Nakamura Y, White R. Amplification of a variable number tandem repeat (VNTR) locus (pMCT118) by the number tandem repeat (VNTR) locus (PMCT118) by the polymerase chain reaction (PCR) and its applicatic

35 Budowle B, Chakraborty R, Giusti AM, Eisenberg AJ, Allen RC. Analysis of the VNTR locus D1S80 by the PCR followed by high-resolution PAGE. Am $f \mathrm{Hum}$ Genet 1991;48:137-44.

36 Boerwinkle E, Xiong W, Fourest E, Chan L. Rapid typing of tandemly repeated hypervariable loci by the polymerase chain reaction: application to the apolipoprotein B 3 hypervariable region. Proc Natl Acad Sci USA 1989;86:212-16.

37 Decorte R, Cuppens H, Marynen P, Cassiman JJ. Rapid detection of hypervariable regions by the polymerase chain reaction technique. DNA Cell Biol 1990;9:461-9.

38 Vuorio AF, Sajantilla A, Hämäläinen T, Syvänen AC, Ehnholm C, Peltonen L. Amplification of the hypervariable region close to the apolipoprotein $B$ gene: application able region close to the apolipoprotein B gene: application to forensic probler.

39 Reynolds RL, Sensabaugh GF. Use of the polymerase chain reaction for typing Gc variants. In: Polesky HF, Mayr WR, eds. Advances in forensic haemogenetics 3. Berlin: Springer-Verlag, 1990:158-61.

40 Saiki RK, Walsh PS, Levenson $\mathrm{CH}$, Erlich HA. Genetic analysis of amplified DNA with immobilized sequencespecific oligonucleotide probes. Proc Natl Acad Sci USA 1989;86:6230-4.

41 Buyse I, Decorte R, Baens $M$, et al. Rapid DNA typing of class II HLA antigens using the polymerase chain reaction and reverse dot blot hybridization. Tissue Antigen 1993;41:1-14.

42 Helmuth R, Fildes N, Blake E, et al. HLA-DQ $\alpha$ allele and genotype frequencies in various human populations,
determined by using enzymatic amplification and oligodetermined by using enzymatic amplification and olig

43 Berg ES, Teisberg P, Olaisen B. Genetic analysis of C4 polymorphism by use of DNA amplification (PCR), polymorphism by use of DNA amplification (PCR), restriction enzymes. Ann Hum Genet 1989;53:221-7.

44 Ugozzoli L, Wallace RB. Application of an allele-specific polymerase chain reaction to the direct determination of ABO blood group genotypes. Genomics 1992;12:670-4.

45 Wu S, Seino S, Bell GI. Human collagen, type II, alpha 1, (COL2A1) gene: VNTR polymorphism detected by gene amplification. Nucleic Acids Res 1990;18:3102.

46 Horn GT, Richards B, Klinger KW. Amplification of a highly polymorphic VNTR segment by the polymerase chain reaction. Nucleic Acids Res 1989;17:2140.

47 Allen RC, Graves G, Budowle B. Polymerase chain reaction amplification products separated on rehydratable polyacrylamide gels and stained with silver. Biotechniques acrylamide gels

48 Waye JS, Michaud D, Bowen JH, Fourney RM. Sensitive and specific quantification of human genomic deoxyribonucleic acid (DNA) in forensic science specimens: casework examples. F Forensic Sci 1991;36:1198-203.

49 Lanzillo JL. Preparation of digoxigenin-labeled probes by the polymerase chain reaction. Biotechniques 1990;8:6212 .

50 Zimran A, Glass C, Thorpe VS, Beutler E. Analysis of 'color PCR' by automatic DNA sequencer. Nucleic Acids Res 1989;17:7538.

51 Robertson J, Ziegle J, Kronick M, Madden D, Budowle B. Genetic typing using automated electrophoresis and fluorescence detection. In: Burke T, Dolf $G$, Jeffreys AJ, Wolff $\mathrm{R}$, eds. DNA fingerprinting : approaches and applications. Basel: Birkhäuser Verlag, 1991:391-8.

52 Sullivan KM, Pope S, Gill P, Robertson JM. Automated
DNA profiling by fluorescent labeling of PCR products. PCR Methods Applic 1992;2:34-40.

$53 \mathrm{Li} \mathrm{H}$, Cui X, Arnheim N. Direct electrophoretic detection of the allelic state of single DNA molecules in human sperm by using the polymerase chain reaction. Proc Natl Acad Sci USA 1990;87:4580-4.

54 Edwards A, Civitello A, Hammond HA, Caskey CT. DNA typing and genetic mapping with trimeric and tetrameric tandem repeats. Am 7 Hum Genet 1991;49:746-56.

55 Beckmann JS, Weber JL. Survey of human and rat microsatellites. Genomics 1992;12:627-31.

56 Gyllensten UB, Erlich HA. Generation of single-stranded DNA by the polymerase chain reaction and its application to direct sequencing of the HLA-DQ $\alpha$ locus. Proc Natl to direct sequencing of the HLA-1
Acad Sci USA 1988;85:7652-6.

57 Bugawan TL, Saiki RK, Levenson $\mathrm{CH}$, Watson RM, Erlich HA. The use of non-radioactive oligonucleotide probes to analyze enzymatically amplified DNA for prenatal diagnosis and forensic HLA typing. Biotechnology 1988;6:943-7.

58 WHO Nomenclature Committee for factors of the HLA system. Nomenclature for factors of the HLA system, 1991. Immunogenetics 1992;36:135-48.

59 Westwood SA, Werrett DJ. An evaluation of the polymerase chain reaction method for forensic applications. Forase chain reaction method for
ensic $S_{\text {ci }}$ Int 1990;45:201-15.

60 Walsh PS, Fildes N, Louie AS, Higuchi R. Report of the blind trial of the Cetus AmpliType HLA DQA forensic deoxyribonucleic acid (DNA) amplification and typing kit. $\mathcal{F}$ Forensic Sci 1991;36:1551-6.

61 National Research Council Committee on DNA Technology in Forensic Science. DNA typing: technical considerations. In: National Research Council, ed. DNA technology in forensic science. Washington: National Academy Press, 1992:51-73.

62 Hopgood R, Sullivan KM, Gill P. Strategies for automated sequencing of human mitochondrial DNA directly from PCR products. Biotechniques 1992;13:82-92.

63 Stoneking M, Hedgecock D, Higuchi RG, Vigilant L, Erlich HA. Population variation of human mtDNA control region sequences detected by enzymatic amplification trol region sequences detected by enzymatic amplification

64 Jeffreys AJ, Royle NJ, Wilson V, Wong Z. Spontaneous mutation rates to new length alleles at tandem-repetitive hypervariable loci in human DNA. Nature 1988;332:27881 .

65 Decorte R, Cassiman JJ. Detection of amplified VNTR alleles by direct chemiluminescence: application to the genetic identification of biological samples in forensic cases. In: Burke T, Dolf $G$, Jeffreys AJ, Wolff R, eds. DNA fingerprinting: approaches and applications. Basel: BNA fingerprinting: approaches

66 Lander ES. DNA fingerprinting on trial. Nature 1989;339:501-5.

67 Budowle B, Giusti AM, Waye JS, et al. Fixed-bin analysis for statistical evaluation of continuous distributions of allelic data from VNTR loci, for use in forensic comparisons. Am $\mathcal{F}$ Hum Genet 1991;48:841-55.

68 Evett IW, Gill P. A discussion of the robustness of methods for assessing the evidential value of DNA single locus profiles in crime investigations. Electrophoresis 1991;12:226-30.

69 National Research Council Committee on DNA Technology in Forensic Science. DNA typing: statistical basis for interpretation. In: National Research Council, ed. DNA technology in forensic science. Washington: National DNA technology in forensic scien.

70 Aldhous P. Geneticists attack NRC report as scientifically flawed. Science 1993;259:755-6.

71 Devlin B, Risch N, Roeder K. Statistical evaluation of DNA fingerprinting: a critique of the NRC's report Science 1993;259:748-9,837.

72 Jeffreys AJ, Neumann R, Wilson V. Repeat unit sequence variation in minisatellites: a novel source of DNA polymorphism for studying variation and mutation by single molecule analysis. Cell 1990;60:473-85.

73 Jeffreys AJ, MacLeod A, Tamaki K, Neil DL, Monckton DG. Minisatellite repeat coding as a digital approach to DNA typing. Nature 1991;354:204-9. 